\title{
Transfer of Drug Resistance to Myxococcus from Bacteria Carrying Drug-resistance Factors
}

\author{
By J. H. PARISH \\ University of Leeds, Department of Biochemistry, Leeds $L S_{2}{ }_{9} L S$
}

(Received I7 July I974; revised 6 November 1974)

\begin{abstract}
SUMMARY
Resistance to chloramphenicol was successfully transferred from strains of Escherichia coli carrying $\mathrm{R}$ factors representative of compatibility groups $\mathrm{F}, \mathrm{W}, \mathrm{S}$ and $\mathrm{N}$ to strains of Myxococcus xanthus and $M$. fulvus. Resistance to kanamycin was transferred from an R factor in group $\mathrm{S}$, and to neomycin from an $\mathrm{R}$ factor of group P. Myxobacterial strains differed in their capacity to take up the resistances and also in the stability of the resistance character. Strains of $M$. fulvus were obtained that acquired resistance to chloramphenicol without exposure to $\mathbf{R}^{+}$ eubacterial strains. Cell-free preparations of all the chloramphenicol-resistant strains catalysed the acetylation of the drug. Chloramphenicol resistance was successfully transferred from the presumed $\mathrm{R}^{+}$strains of Myxococcus and also from the spontaneously occurring chloramphenicol-resistant $M$. fulvus to other Myxococcus strains. Moreover, recombinants resistant to both rifampicin and 5-fluorouracil were obtained, though infrequently, by mixing Myxococcus strains resistant to rifampicin and chloramphenicol with other myxococci resistant to 5fluorouracil, both when the chloramphenicol resistance was derived from $\mathrm{S}-\mathrm{a}$ (group W) and when it was the endogenous $M$. fulvus resistance. Thus it appears that S-a and a new chloramphenicol resistance factor from $M$. fulvus will mobilize a chromosomal genetic marker in Myxococcus.
\end{abstract}

\section{INTRODUCTION}

Members of the order Myxobacteriales are Gram-negative rods that demonstrate gliding motility. They form fruiting bodies and also demonstrate morphogenesis of the cell. In the lower myxobacteria (families Myxococcaceae, Archangiaceae and Cystobacteraceae), the morphogenesis consists of the formation of myxospores of grossly different morphology to the vegetative rods. The myxobacteria are thus valuable in studying organism-organism interaction and morphogenesis in prokaryotes (Dworkin, 1973).

Genetic analysis would be of great value in resolving the mechanisms that control these processes. I report the transmission of antibiotic resistance by myxobacteria with a view to establishing the foundation of gene transfer by conjugation.

The organisms used are of the genus Myxococcus (Myxococcaceae). These bacteria are the most convenient for experimental study as, unlike most myxobacteria, $M$. xanthus FB (Dworkin, 1962) grows in a dispersed state in liquid culture and moreover can be induced synchronously to produce myxospores in liquid (Dworkin \& Sadler, 1966).

\section{METHODS}

Media. For experiments involving Myxococcus, including mixed growth of Myxococcus with other bacterial species, the bacteria were grown in $\mathrm{CT}$ medium ( $\%$, w/v, Bactocasitone; 
Table I. Bacterial strains

\begin{tabular}{|c|c|c|c|c|}
\hline Organism & Strain & Genetic markers* & Origin & Reference \\
\hline \multirow[t]{4}{*}{ Escherichia coli } & $\begin{array}{l}\mathrm{J} 53 \\
\mathrm{~J} 53-1\end{array}$ & $\begin{array}{l}\text { KI } 2 \mathrm{~F}^{-} l a c^{+} \text {met pro } \\
\text { nal }\end{array}$ & $\begin{array}{l}\text { S. Baumberg } \\
\text { S. Baumberg }\end{array}$ & Clowes \& Hayes (1968) \\
\hline & 362 & $\mathrm{~K}_{\mathrm{I} 2} \mathrm{~F}^{-}$lac his pro trp & & Clowes \& Hayes (1968) \\
\hline & $\begin{array}{l}J 62-I \\
J 62-2\end{array}$ & & $\begin{array}{l}\text { S. Baumberg } \\
\text { S. Baumberg }\end{array}$ & \\
\hline & 1100 & $\underset{\text { endo }}{\mathrm{K}_{12} \mathrm{~F}^{-} \mathrm{T}_{\mathrm{I}}{ }^{\mathrm{r}} \mathrm{T}{ }^{\mathrm{r}} \mathrm{m}_{\mathrm{B}}{ }^{+} \mathrm{r}_{\mathrm{B}}{ }^{+}}$ & K. Murray & $\begin{array}{l}\text { Yoshimori, Roulland- } \\
\text { Dussoix \& Boyer (I972) }\end{array}$ \\
\hline Serratia marcescens & K5.8 & rif nal & This work & \\
\hline Pseudomonas fuorescens & P.f.(RP4) & (See Table 2) & & \\
\hline \multirow[t]{7}{*}{ Myxococcus xanthus } & A & (See text) & This work & \\
\hline & AI & rif & This work & \\
\hline & A44 & rif & This work & \\
\hline & B & & NCIB & \\
\hline & B26 & rif & This work & \\
\hline & B27 & $f u$ & This work & \\
\hline & $\mathrm{FB}_{\mathrm{t}}$ & pig & R. P. Burchard & $\begin{array}{l}\text { Burchard \& Dworkin } \\
(\mathrm{I} 966 b)\end{array}$ \\
\hline \multirow[t]{3}{*}{ Myxococcus fulvus } & M & & This work & \\
\hline & M26 & rif & This work & \\
\hline & M27 & $f u$ & This work & \\
\hline
\end{tabular}

* $f l u, n a l$ and $r i f$ are resistance to 5 -fluorouracil, nalidixic acid and rifampicin respectively; Tr and T5 are bacteriophage $\mathrm{T}_{\mathrm{I}}$ and $\mathrm{T}_{5} ; \mathrm{m}_{\mathrm{B}}$ and $\mathrm{r}_{\mathrm{B}}$ are the modification and restriction enzymes of $E$. coli $\mathrm{B}$; endo, endonuclease; pig, pigment.

Difco). For experiments involving exclusively bacteria other than Myxococcus, the medium was nutrient broth containing $(\%, \mathrm{w} / \mathrm{v})$ : tryptone, I; yeast extract, $0.5 ; \mathrm{NaCl}, 0.5$. Solid media contained $\mathrm{r} \cdot 5 \%(\mathrm{w} / \mathrm{v})$ agar (London Analytical and Biological Media, Ltd). Minimal salts agar was that of Clowes \& Hayes (I968) supplemented with the amino acids specified at a concentration of $0.01 \%$.

Growth conditions. Bacteria were grown in shake culture and incubated (either on agar or as stationary liquid cultures) at $30^{\circ} \mathrm{C}$ unless otherwise specified. The rate of expansion of surface colonies of Myxococcus was measured by the method of Burchard (1974). The 'fruiting medium' for Myxococcus was $0.02 \% \mathrm{CT}$ supplemented with the inorganic salts used by Burchard (I974) and solidified with agar ( $1.5 \%$ w/v). Plates were inoculated in the centre and incubated at $100 \%$ relative humidity. The organisms form fruiting bodies in concentric rings as described for Archangium violaceum by Reichenbach (I965) and for $M$. xanthus by Burchard (1974).

Drugs were used at the following concentrations $(\mu \mathrm{g} / \mathrm{ml})$ : rifampicin, 4 ; nalidixic acid, 25; 5 -fluorouracil, I00; streptomycin sulphate, 50; chloramphenicol, usually 25; kanamycin, 25; neomycin, 25; carbenicillin, 500. For certain experiments different concentrations of chloramphenicol were employed; details appear in Results.

Bacterial strains. These are listed in Table $\mathrm{I}$.

Serratia marcescens $\mathrm{K} 5.8$ was obtained from $S$. marcescens $\mathrm{K} 5$ (NCIB2847) by selecting spontaneous mutants resistant to rifampicin and selecting from such a mutant a spontaneous mutant resistant to nalidixic acid.

Myxococcus xanthus strains A and B are clones of $M$. xanthus FB (Dworkin, I962). Myxococcus xanthus A was selected on the basis of a very low frequency of phenotypically phageresistant colonies when plated in the presence of excess (phage/bacterium: 10/1) bacteriophage MXI (Burchard \& Dworkin, I966a). The $M$. xanthus FB from which the strain was 
Table 2. Plasmids

\begin{tabular}{|c|c|c|}
\hline Plasmid & $\begin{array}{l}\text { Resistance and } \\
\text { other markers* }\end{array}$ & $\begin{array}{l}\text { Compatibility } \\
\text { group }\end{array}$ \\
\hline $\mathrm{R} I d r d \mathrm{I} 9$ & chl kan str sul & FII \\
\hline $\begin{array}{l}\text { RI } d r d \text { I9-I } \\
\text { RI } \cdot 19-2 \\
\text { RI } \\
\text { RP4 } \\
\text { RI } 44 d r d 3 \\
\text { R }_{3} 87\end{array}$ & $\begin{array}{l}\text { chl str sul } \\
\text { chl str sul tra- } \\
\text { chl str amp } \mathrm{r}_{\mathrm{RI}}{ }^{+} \mathrm{m}_{\mathrm{RI}^{+}} \\
\text {car neo tet } \\
\text { kan } \\
\text { chl str }\end{array}$ & $\begin{array}{l}\text { FII } \\
\text { FII } \\
\text { FII } \\
\text { P } \\
\text { I } \\
\text { K }\end{array}$ \\
\hline $\begin{array}{l}\text { R57b } \\
\text { R390 } \\
\text { S-a } \\
\text { R478 }\end{array}$ & $\begin{array}{l}\text { chl amp sul gen } \\
\text { chl amp str sul tet hsp II } \\
\text { chl kan sul str } \\
\text { chl kan tet }\end{array}$ & $\begin{array}{l}\mathrm{C} \\
\mathrm{N} \\
\mathrm{W} \\
\mathrm{S}\end{array}$ \\
\hline
\end{tabular}

\author{
Reference \\ Lawn, Meynell, \\ Meynell \& Datta (1967) \\ S. Baumberg (see text) \\ This work \\ Yoshimori et al. (1972) \\ Saunders \& Grinsted (1972) \\ Lawn et al. (1967) \\ Hedges, Datta, Coetzee \& \\ Dennison (I973) \\ Witchitz \& Chabbert (I972) \\ Ingram ( I 973) \\ Hedges \& Datta (197I) \\ Hedges, Rodriguez- \\ Lemoine \& Datta (1975)
}

* Resistance markers are as follows: chl, chloramphenicol; kan, kanamycin; str, streptomycin; sul, sulphonamides; amp, ampicillin; car, carbenicillin; neo, neomycin; tet, tetracycline; gen, gentiomycin. $\mathrm{r}_{R 1}{ }^{+}$, $\mathrm{m}_{\mathrm{RI}}{ }^{+}$and $h s p \mathrm{II}$ are restriction and modification systems; tra, transferability.

selected was obtained from Professor Dworkin's culture collection. Myxococcus xanthus B is a clone of $M$. xanthus $\mathrm{FB}$ (NCIB94I2); the organism produces predominantly tan colonies during the spontaneous segregation of colour variants that is characteristic of $M$. xanthus (Burchard \& Dworkin, I966b).

Myxococcus fulvus $\mathrm{M}$ is a clone of strain Mittelamerika which was a gift from $\mathrm{Dr} \mathrm{H}$. Kühlwein. The original strain did not grow in a disperse form in shake culture. Strain $M$ is a variant that grows as rosettes each composed of approximately 100 organisms; the rosettes are easily dispersed by agitation. This type of behaviour is also characteristic of certain $M$. xanthus strains (R. P. Burchard, unpublished). Certain derivatives of strain $M$ are not disperse-growing (see Results).

All the Myxococcus strains are hosts for bacteriophage MXI.

Myxococcus strains resistant either to rifampicin or 5 -fluorouracil were obtained by exposing bacteria in $\mathrm{IO}^{-1} \mathrm{M}$-potassium phosphate buffer $\mathrm{pH} 7.6$ to u.v. light to approximately $0 . \mathrm{I} \%$ survival, growing the survivors to approximately $10^{8}$ colony-forming units (c.f.u.)/ml and plating on CT agar containing the drug. Resistant colonies were cloned three times on CT agar containing the drug and were grown in CT. The efficiency of plating (e.o.p.) on CT agar containing the drug was determined. Certain strains (notably those derived from $M$. xanthus A) were unstable and showed low e.o.p. in the presence of the drug. Of those used, A44 rif, B26 rif, B27 flu, M26 rif and M27 flu all gave e.o.p. of 85 to $100 \%$ on agar containing the drug and were regarded as 'stable'. Myxococcus xanthus AI rif was originally unstable (e.o.p. approximately $40 \%$ on rifampicin) at the time the organism AI(RI.I9) chl (see Results) was obtained. Over a period of six months this organism had become stable with regard to rifampicin resistance and its segregant $\mathrm{AI}-\mathrm{I}$ (see Results) is also stably rifampicin resistant.

Myxococcus fulvus M2, M3 and M7 (all $\mathrm{chl}$ ) arose spontaneously on a single occasion (see Results). These, and certain other chloramphenicol-resistant derivatives of strain $\mathrm{M}$ obtained from mixed growth with $\mathrm{R}^{+}$strains of Escherichia coli, are non-disperse. Such organisms grow in shake culture in the form of spheres, reaching a maximum diameter of approximately $3 \mathrm{~mm}$, similar to a 'rough' variant of $M$. xanthus $\mathrm{FB}_{\mathrm{t}}$ (R. P. Burchard, unpublished). 
They were cloned either by crushing the spheres and streaking or by streaking colonies picked from agar plates.

Plasmids. $\mathrm{R}$ factors used in this work are listed in Table 2. RrdrdI9-I is a kanamycinsensitive spontaneous segregant of R $\mathrm{r} d r d \mathrm{r} 9$, obtained by Drs Baumberg and Dennison. $\mathrm{R}$ factors were transferred between $E$. coli hosts by the methods of Datta \& Hedges (1972). $\mathrm{RI} d r d \mathrm{I} 9$ was transferred from $E$. coli $\mathrm{J} 53$ to $S$. marcescens $\mathrm{K} 5.8$ by incubating a mixture of the bacteria at $30{ }^{\circ} \mathrm{C}$ for $24 \mathrm{~h}$ and plating on agar containing rifampicin, nalidixic acid and chloramphenicol. Colonies were tested on CT agar and on CT agar containing kanamycin. (The pink colour of $S$. marcescens is not well developed on the selection plates.) Serratia marcescens carrying kanamycin resistance (about $80 \%$ of those tested) was used.

The plasmid RI. I9-2 chl tra was obtained as follows. Escherichia coli J62-I(RIdrdr9-I) was plated on nutrient agar in the presence of a high concentration of bacteriophage MS2 (Davis, Strauss \& Sinsheimer, I96I). Colonies, shown to be resistant to phage MS2, were grown in nutrient broth, mixed with $E$. coli $\mathrm{J} 53$, incubated for $24 \mathrm{~h}$, and plated on minimal salts agar supplemented with chloramphenicol, methionine and proline. Out of 30 colonies tested, five appeared to be transfer-defective (frequency of transfer $<\mathrm{IO}^{-6}$ ) in this screen. These five strains were crossed with $E$. coli $\mathrm{J}_{53}\left(\mathrm{R} \mathrm{R}_{44} d_{r} d_{3}\right)$ and plated on nutrient agar containing chloramphenicol, nalidixic acid and kanamycin. Colonies growing on this medium were tested on minimal salts agar supplemented with (i) histidine, proline, tryptophan, nalidixic acid, chloramphenicol and kanamycin, and (ii) methionine and proline. Those that grew on (i) but not (ii), i.e. derivatives of E. coli J62-I, were crossed with E. coli 553 and plated on minimal salts agar supplemented with methionine, proline and chloramphenicol. Kanamycin-resistant colonies were rejected. The others were tested for their ability to transfer chloramphenicol resistance to strain $\mathrm{J} 62-\mathrm{I}$. After this screen, two of the original five possible tra plasmids were found to have a transfer frequency of less than $\mathrm{IO}^{-6}$ from $\mathrm{J} 53$ to $\mathrm{J} 62-\mathrm{I}$, and vice versa, in four independent tests in each direction. The fact that the chloramphenicol resistance could be mobilized by RI $44 d r d 3$ shows the independent character of the $c h l$ gene. One plasmid, RI . I9-2, was used as a tra mutant of RIdrdI9-I.

Genetic exchange involving Myxococcus. Donor and recipient strains (approximately $\mathrm{IO}^{8}$ c.f.u./ml in CT medium) were mixed and incubated in tubes overnight. Experiments involving non-disperse strains of $M$. fulvus used 3 or 4 spheres of organism in a total volume of $5 \mathrm{ml}$. The mixtures were plated on CT agar containing drugs to select against both parents of the cross. When streptomycin was used to select against $E$. coli $\mathrm{R}^{+}$strains the concentration of this drug $(50 \mu \mathrm{g} / \mathrm{ml})$ was higher than the resistance conferred by str markers in any of the $\mathrm{R}$ factors (I $5 \mu \mathrm{g} / \mathrm{ml}$ ). Colonies of $E$. coli (presumably spontaneous str $A$ mutants) were ignored. Myxococcus exconjugant colonies appeared after 5 to 6 days ( 7 to 8 days on plates containing 5-fluorouracil). Drug-resistant strains of Myxococcus are referred to as the strain designation with the apparently-transferred $\mathrm{R}$ factor in brackets. In the case of RIdrdr9, the designation for Myxococcus is simply (RI.19) as there is no evidence that derepressed transfer capacity is maintained in Myxococcus.

In those experiments in which chloramphenicol-resistant Myxococcus strains were used as donors, these were grown in CT medium containing chloramphenicol and the bacteria were washed by centrifugation and resuspended in CT before mixing.

Acetylation of chloramphenicol. Chloramphenicol acetyltransferase (EC. 2 -3 - I .28) cannot be assayed by the colorimetric method of Shaw \& Brodsky (1968) in crude extracts of Myxococcus because of the high background of acetyl CoA hydrolase activity. The following radioactive assay based on the methods of Shaw (1967) was employed. Bacteria were washed, resuspended in $0.0 \mathrm{I} \mathrm{M}$-tris- $\mathrm{HCl}$ buffer $\mathrm{pH} 7.8\left(\mathrm{IO}^{12} \mathrm{c.f.u} . / \mathrm{ml}\right)$ and sonicated $(4 \mathrm{~A}$, 
I min, $0{ }^{\circ} \mathrm{C}$; Dawe Soniprobe). Debris was removed by centrifugation ( $18000 \mathrm{~g}$ for $30 \mathrm{~min}$ ). For many experiments, the unfractionated supernatant was employed. Protein was assayed by the method of Lowry, Rosebrough, Farr \& Randall (I95I) using bovine serum albumin for calibration. For some purposes the protein precipitated by ammonium sulphate $(50 \%$ saturation) was used. Protein solution and added buffer. (protein concentration $5 \mathrm{mg} / \mathrm{ml}$ ), acetyl CoA (final concentration $0 . \mathrm{I} \mathrm{mM}$ ) and dichloracetyl $\left[\mathrm{I}-{ }^{14} \mathrm{C}\right]$ chloramphenicol $(8.8 \mathrm{Ci} /$ mmol; ro $\mu \mathrm{Ci} / \mathrm{ml}$ ) were incubated at $37^{\circ} \mathrm{C}$. Samples were extracted three times with 2 vol. ethyl acetate; the solvent was removed by rotatory evaporation and the residue was redissolved in a small volume of ethyl acetate and spotted on to a thin-layer chromatographic plate (stationary phase Kieselgel Typ G, $0.5 \mathrm{~mm}$; Merck, Darmstadt, Germany). The chromatograms were developed in methanol and chloroform $(5: 95, \mathrm{v} / \mathrm{v})$ and exposed to $X$-ray film. The films were developed and the film blackening was measured at $450 \mathrm{~nm}$ in a Pye/Unicam SPI80o spectrophotometer fitted with a gel scanning attachment.

For certain experiments bacteria were grown in the presence of dichloracetyl $\left[\mathrm{I}^{14} \mathrm{C}\right] \mathrm{ch}$ loramphenicol and the medium was assayed for radioactive chloramphenicol and acetyl chloramphenicols. The medium was extracted twice with I vol. ethyl acetate and the ethyl acetate was reduced in volume and the products analysed as above.

Carotenoids. Recombinants of strains $\mathrm{B}$ and $\mathrm{M}$ were identified by analysis of their carotenoids. Bacteria were streaked on CT agar and incubated under uniform tungsten-light illumination for 6 days. The bacteria were scraped off, extracted with acetone, and spectra of these extracts were recorded between 325 and $600 \mathrm{~nm}$. The spectra showed maxima at $377,400,425,450,477$ and $507 \mathrm{~nm}$. The ratio $A_{377}$ to $A_{400}$ is characteristic of the strains $(0.8$ to $\mathrm{I} \cdot 0$ for strain $\mathrm{B} ; \mathrm{I} \cdot 2$ to $\mathrm{I} \cdot 4$ for strain $\mathrm{M})$. Additionally, the carotenoids were analysed by thin-layer chromatography using the method of Kleinig \& Reichenbach (I973). Components were resolved with the following $R_{F}$ values and appearances, the fluorescent spots being visualized under u.v. light: 0.0 (yellow), 0.08 (red), 0.13 (blue fluorescence), 0.20 (orange), 0.90 (diffuse, orange), 0.97 (red), 0.98 (orange). The components with $R_{F} 0.13$ and 0.90 are characteristic of $M$. fulvus $\mathbf{M}$.

\section{RESULTS}

\section{Transfer of drug resistance to Myxococcus}

Chloramphenicol-resistant derivatives of $M$. xanthus A I were obtained from mixtures of this strain with $E$. coli $\mathrm{J} 53(\mathrm{RI} d r d \mathrm{I} 9)$. Chloramphenicol-resistant $E$. coli formed a lawn on the selection plates (rifampicin plus chloramphenicol) due either to spontaneous rif mutants or loss of rifampicin during the 6-day incubation. Myxococcus xanthus colonies appeared initially as plaques in this lawn. After further incubation ( 4 days), yellow $M$. xanthus colonies were visible in the plaques. Alternatively, picks from the centres of the plaques yielded viable $M$. xanthus organisms.

An objection to this procedure of scoring 'plaques' in such gene-exchange experiments is that the limited growth of $E$. coli $\mathrm{J}_{53}(\mathrm{R} \mathrm{I} d r d \mathrm{I} 9)$ might reduce the effective concentration of chloramphenicol in the agar and thus permit selection of chromosomal mutations in $M$. xanthus to produce chloramphenicol resistance. Subsequent studies involving $\mathbf{R}$ factors employed streptomycin to select against E. coli. All our Myxococcus strains are streptomycin resistant and, at the concentration of streptomycin used, growth of the donor strains was totally inhibited. Although certain plates contained isolated streptomycin-resistant $E$. coli colonies, the numbers (in no case more than 7 colonies) were insufficient to detoxify chloramphenicol in the agar. The results are summarized in Table 3. In addition to chlor- 
Table 3. Summary of transfer of $R$ factor determinants from eubacteria to Myxococcus

Incubations were performed as in Methods with $5 \times 10^{9}$ c.f.u. eubacterial donor and typically $10^{9}$ c.f.u. Myxococcus before incubation. Numbers refer to drug-resistant c.f.u. per $10^{8}$ surviving myxococci. Counterselection was achieved by plating on a mixture of the drug plus streptomycin, except when the donor was P. fluorescens (RP4) in which case the mixture was plated on CT agar containing the appropriate drug and the plates were incubated at $37^{\circ} \mathrm{C}$ as the donor does not grow at this temperature. The control (Myxococcus incubated in the absence of $\mathrm{R}^{+}$bacteria) showed no colonies ( $<\mathrm{I}$ per $1 \mathrm{O}^{8} \mathrm{c.f}$.u.) except for certain strains plated on either carbenicillin or neomycin. In these cases the transfer is recorded by the symbol '?'. NT, Not tested.

Recipient

\begin{tabular}{|c|c|c|c|c|c|c|c|}
\hline \multirow[b]{2}{*}{ Donor } & \multirow[b]{2}{*}{ Plasmid } & \multirow[b]{2}{*}{$\begin{array}{l}\text { Resis- } \\
\text { tance }\end{array}$} & \multicolumn{5}{|c|}{ Nectpien } \\
\hline & & & $\underset{\mathrm{A}}{M .}$ xanthus & $\begin{array}{c}\text { M. xanthus } \\
\text { A44 }\end{array}$ & $\begin{array}{c}\text { M. xanthus } \\
\mathrm{FB}_{\mathrm{t}}\end{array}$ & $\underset{\mathrm{B}}{M . x a n t h u s}$ & $\underset{\mathbf{M}}{M . f u l v u s}$ \\
\hline \multirow[t]{2}{*}{ E. coli $\mathrm{J} 53$} & $\mathrm{R}_{\mathrm{I}} d r d{ }_{19}$ & chl & 9 & $<$ I & $<\mathbf{I}$ & 10 & 27 \\
\hline & & kan & $<\mathrm{I}$ & $<1$ & $<\mathrm{I}$ & $<\mathrm{I}$ & $<\mathrm{I}$ \\
\hline S. marcescens $\mathrm{K} 5.8$ & $\mathrm{R} \mathrm{I} d r d{ }_{19}$ & $\operatorname{chl}$ & $<$ I & NT & NT & $<\mathrm{I}$ & $<\mathrm{I}$ \\
\hline E. coli $62-1$ & RI $d r d \mathrm{Ig}-\mathrm{I}$ & chl & 10 & NT & NT & 30 & 30 \\
\hline E. coli 62-I & RI.I9-2 & $c h l$ & I5 & NT & NT & 27 & 60 \\
\hline E. coli 1100 & RI & chl & 2 & NT & NT & 10 & 8 \\
\hline E. coli $\mathrm{J} 53$ & $\mathrm{R}_{144 d r d 3}$ & kan & $<$ I & NT & NT & $<\mathrm{I}$ & $<1$ \\
\hline E. coli $\mathrm{J} 53$ & $\mathrm{R}_{3} 87$ & chl & $<$ I & $<\mathrm{I}$ & NT & $<\mathrm{I}$ & $<\mathrm{I}$ \\
\hline \multirow[t]{2}{*}{ P. fluorescens } & $\mathrm{RP}_{4}$ & car & 100 & NT & NT & $?$ & $<\mathrm{I}$ \\
\hline & & neo & 30 & NT & NT & 20 & $?$ \\
\hline E. coli $\mathrm{J} 53$ & $\mathrm{R} 57 \mathrm{~b}$ & $\operatorname{chl}$ & 3 & NT & NT & 120 & 60 \\
\hline \multirow[t]{2}{*}{ E. coli $\mathrm{J} 62-2$} & $\mathrm{R} 478$ & chl & $<\mathrm{I}$ & NT & $<$ I & $I 60$ & 160 \\
\hline & & kan & $<\mathrm{I}$ & NT & $<\mathrm{I}$ & $<$ I & 100 \\
\hline E. coli $\mathrm{J} 53-\mathrm{I}$ & $\mathrm{S}-\mathrm{a}$ & $\operatorname{chl}$ & $<\mathrm{I}$ & NT & $<\mathrm{I}$ & 100 & I 40 \\
\hline E. coli $\mathrm{j} 62-2$ & R390 & chl & $<\mathrm{I}$ & NT & NT & 16 & $<\mathrm{I}$ \\
\hline
\end{tabular}

Table 4. Summary of $R$ factors transferred to Myxococcus

+ , Transferable and surviving; -, not transferable; a, abortive; ?, cannot be tested (see text). Blank entries were not tested. Myxococcus strains as in Table $\mathrm{I}$.

\begin{tabular}{|c|c|c|c|c|c|c|c|c|}
\hline \multirow[b]{2}{*}{ Plasmid } & \multirow[b]{2}{*}{$\begin{array}{l}\text { Compatibility } \\
\text { group }\end{array}$} & \multirow[b]{2}{*}{ Resistance } & \multicolumn{6}{|c|}{ Myxococcus strain } \\
\hline & & & A & AI & A44 & B & $\mathrm{FB}_{\mathrm{t}}$ & M \\
\hline \multirow[t]{2}{*}{$\mathrm{R} \mathrm{I} d r d \mathrm{I} 9$} & FII & chl & a & + & - & + & - & t \\
\hline & & kan & - & - & - & - & - & - \\
\hline RI & FII & chl & a & & & + & & + \\
\hline \multirow[t]{2}{*}{$\mathrm{RP}_{4}$} & $\mathrm{P}$ & car & a & & & ? & & - \\
\hline & & neo & + & & & + & & ? \\
\hline $\mathrm{R}_{144 d r d_{3}}$ & I & kan & - & - & & - & & - \\
\hline$R_{3} 87$ & $\mathrm{~K}$ & $c h l$ & - & & - & - & & - \\
\hline R $57 \mathrm{~b}$ & $\mathrm{C}$ & chl & a & & & + & & + \\
\hline R390 & $\mathrm{N}$ & $c h l$ & - & & & + & - & - \\
\hline \multirow[t]{2}{*}{$\mathrm{R} 478$} & $\mathrm{~S}$ & $c h l$ & - & & & + & - & + \\
\hline & & kan & - & & & - & - & + \\
\hline S-a & W & chl & - & & & + & - & + \\
\hline
\end{tabular}

amphenicol, attempts were made using suitable donor strains to select for Myxococcus strains resistant to neomycin, carbenicillin and kanamycin. Other resistance determinants carried by the $\mathrm{R}$ factors (see Table 2 ) are not suitable for study, either because myxobacteria are inherently resistant (ampicillin, streptomycin and sulphonamides) or (in the case of tetracycline) the drug is unstable and might decompose during the prolonged incubations.

Drug-resistant derivatives of Myxococcus strains A, B and $\mathrm{M}$ were picked and streaked on CT agar containing the appropriate drug. Strains A(RI. I9) chl, A(RP4) car, and $\mathrm{A}\left(\mathrm{R}_{57} \mathrm{~b}\right)$ $c h l$ were found to be incapable of further growth in the presence of the drug and are regarded 


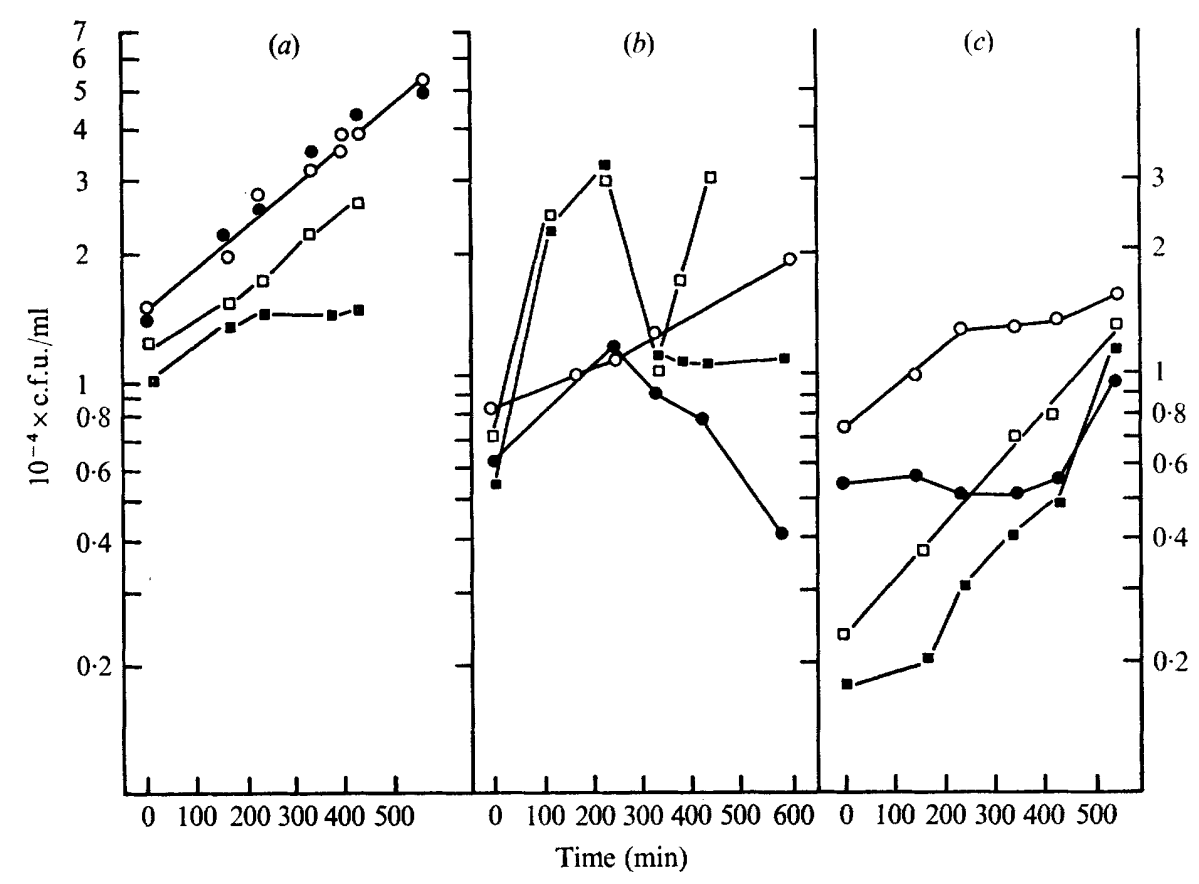

Fig. I. Growth of chloramphenicol-resistant Myxococcus strains upon transfer from chloramphenicol to CT medium. A culture in CT plus chloramphenicol was diluted $\times 10^{3}$ into $C T$ and incubated on CT (open symbols) and CT plus chloramphenicol (solid symbols). (a), O, , AI(RI . I9); $\square, \boldsymbol{\square}$,

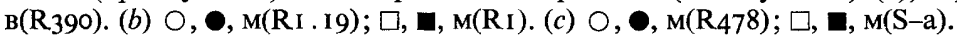

tentatively as abortive. Isolates of $\mathrm{M}(\mathrm{R} 478) \mathrm{chl}$ were tested on kanamycin and $80 \%$ were found to be kanamycin resistant. All strains originally scored as $\mathrm{M}(\mathrm{R} 478) \mathrm{kan}$ were found to be chloramphenicol resistant. On the basis of these data and those in Table 3, the transfer of $\mathrm{R}$ factors to Myxococcus is summarized in Table 4.

In addition to these strains, a set of chloramphenicol-resistant derivatives of $M$. fulvus $\mathrm{M}$ appeared spontaneously with a frequency of approximately $\mathrm{IO}^{-7}$. The appearance of such mutants was not observed on any subsequent occasion. The chloramphenicol-resistant phenotype has also been obtained in derivatives of $M$. xanthus $\mathrm{FB}_{\mathrm{t}}$ (R. P. Burchard and J. H. Parish, unpublished). This phenotype did not appear in controls with cultures used for the incubations in Table 3, nor has it ever been observed in strains A, AI, A44 or B. All the chloramphenicol-sensitive strains described here plate with $100 \%$ efficiency on CT agar containing $5 \mu \mathrm{g}$ chloramphenicol $/ \mathrm{ml}$; a concentration of Io $\mu \mathrm{g}$ of the $\mathrm{drug} / \mathrm{ml}$ is inhibitory (no detectable growth in liquid medium and an e.o.p. of less than $5 \times 10^{-8}$ ).

\section{Stability and growth of chloramphenicol-resistant strains of Myxococcus}

The e.o.p. of chloramphenicol-resistant strains on chloramphenicol was measured during growth in the presence and absence of chloramphenicol, in the light of the observation (R. P. Burchard and J. H. Parish, unpublished) that after one generation $\mathrm{FB}_{\mathrm{t}}$ chl organisms showed a loss of chloramphenicol resistance. Strain AI(RI . I9) $\mathrm{chl}$ has changed during the period of one year since its original isolation. Initially, chloramphenicol-grown bacteria demonstrated an e.o.p. on chloramphenicol of $20 \%$. Recent experiments show an e.o.p. of I00\%. All other chloramphenicol-resistant strains have plated with consistently high 


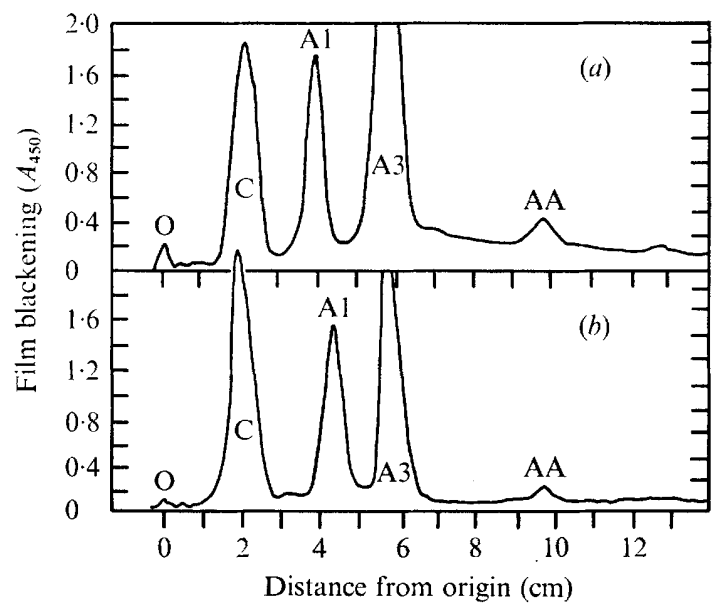

Fig. 2. Acetylation of chloramphenicol by extracts of chloramphenicol-resistant strains of $E$. coli and $M$. xanthus. Experimental details are described in Methods. Equal concentrations of protein were used in each case. Tracings of film blackening of autoradiographs of thin-layer chromatographic plates are shown. O, origin; C, chloramphenicol; AI, I-acetylchloramphenicol; A3, 3-acetylchloramphenicol, AA, I,3-diacetylchloramphenicol. Results were obtained after incubations with extracts of (a) E. coli J53(RIdrd19) for 10 min and (b) M. xanthus AI(RI . 19) chl for $2 \mathrm{~h}$.

efficiency (approximately $100 \%$ ) on CT agar containing chloramphenicol when grown in the presence of chloramphenicol from the time of their original isolation. The effects of transferring such strains to CT medium are shown in Fig. I. The anomalous growth of $\mathrm{M}-$ strains is due to aggregation and dispersion which show apparent phase variation. The data show that, with the exception of $\mathrm{M}(\mathrm{RI}$. I9) $\mathrm{chl}$, none of the organisms show loss of resistance from the formerly resistant population although certain strains, such as $\mathrm{B}(\mathrm{R} 390) \mathrm{chl}$, show a rapid segregation of chloramphenicol-sensitive organisms during division. After 15 generations, the e.o.p. on CT plus chloramphenicol was: $\mathrm{AI}(\mathrm{RI} . \mathrm{I} 9), \mathrm{I} \cdot 7 \times \mathrm{IO}^{-6} ; \mathrm{M}(\mathrm{RI}), 4.5 \times \mathrm{IO}^{-5}$; $\mathrm{M}(\mathrm{S}-\mathrm{a}), 7.5 \times 10^{-1} ; \mathrm{M}(\mathrm{R} 478), 5 \times 10^{-7}, \mathrm{M}(\mathrm{RI} .19),<10^{-7} ; \mathrm{B}(\mathrm{R} 390),<10^{-7}$. Such experiments are not possible with totally non-disperse strains. These were cloned by streaking on either $\mathrm{CT}$ alone or CT plus chloramphenicol. Of I $2 \mathrm{M} 7$ clones on CT, I I were chloramphenicol resistant; of $\mathrm{I}_{2} \mathrm{M}\left(\mathrm{R}_{57} \mathrm{~b}\right)$ clones on CT, Io were chloramphenicol resistant. In both cases I 2 out of $\mathrm{I} 2$ clones on chloramphenicol were chloramphenicol resistant upon transfer to medium containing chloramphenicol.

An alternative to studying exponential growth in Myxococcus is to measure the rate of increase in colony diameter. This function, which is primarily a measure of motility, is linear in $M$. xanthus $\mathrm{FB}_{\mathrm{t}}$ (Burchard, I974). Strains derived from $M$. fulvus showed a lag of 50 to Ioo $\mathrm{h}$ during which colony spreading was very slow, before linear growth developed. In calculating the rate of spreading (Table 5) these lag periods have been neglected and the rates are those achieved after the lag. The motility of $M$. xanthus AI(RI . I9) chl was severely limited by chloramphenicol despite its stable genotype and good growth (Fig. I). The motility of other chloramphenicol-resistant strains was only partially limited. The limitation may have been due to motility being sensitive to low intracellular concentrations of the drug remaining in these strains, despite the presence of acetylase activity (next section).

On fruiting agar, all the strains formed normal fruiting bodies in the absence of chloramphenicol. In the presence of chloramphenicol, strains AI(RI. 19), B(RI. I9), B(R390), M2, M(RI . I9), M(RI), M(S-a) and M(R478) formed mature fruiting bodies, $M\left(R_{57} b\right)$, M3 and 


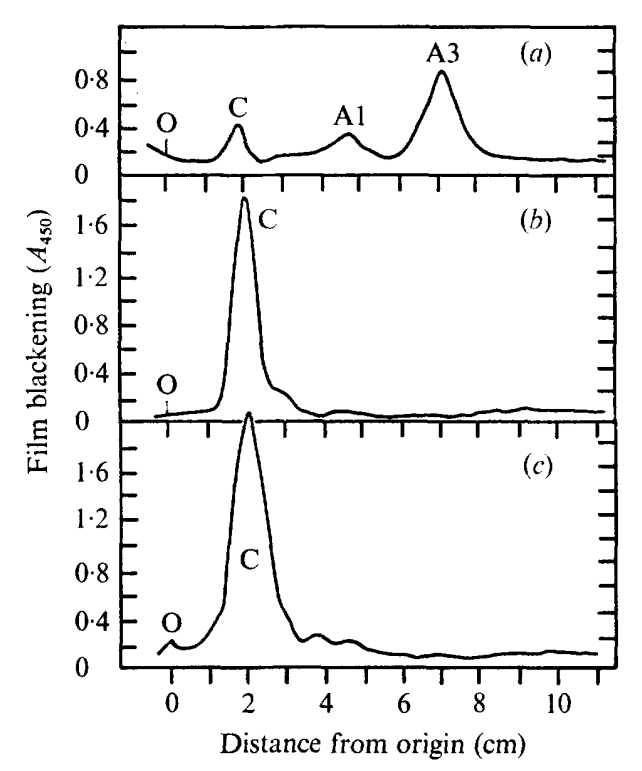

Fig. 3

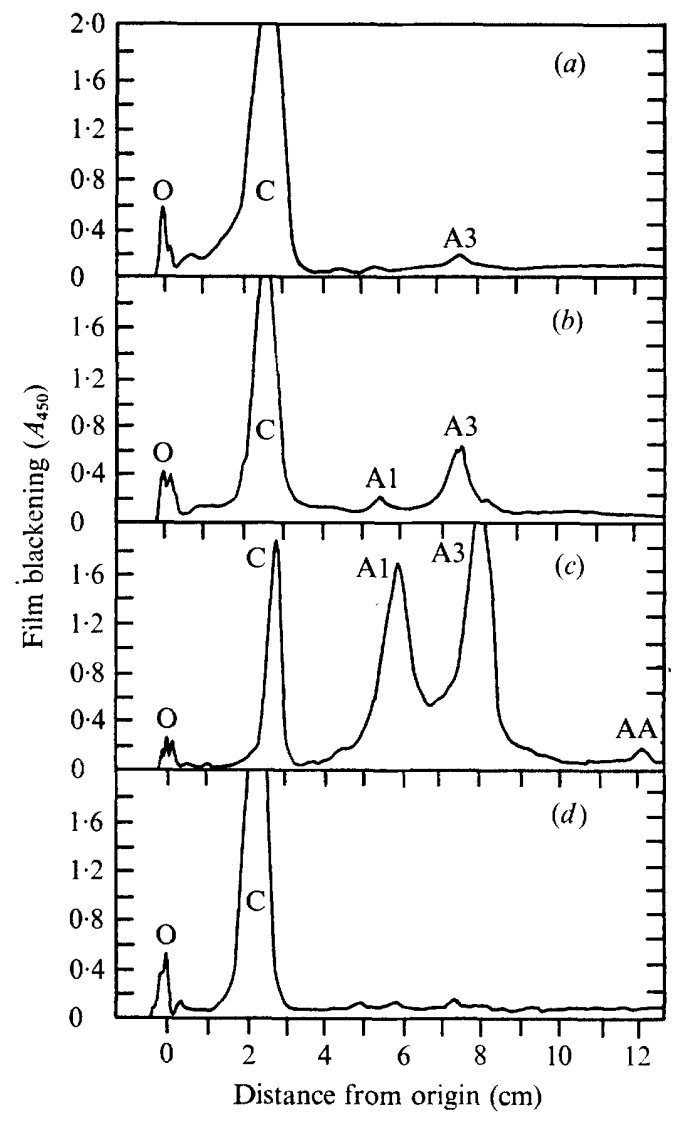

Fig. 4

Fig. 3. Acetylation of chloramphenicol by extracts of strains derived from $M$. xanthus AI. Extracts were fractionated by ammonium sulphate precipitation. Incubations were as in Fig. 2 , for $2 \mathrm{~h}$. (a) AI (RI . I9) $c h l$ plus acetyl CoA; (b) A (R I . I9) $c h l$ without acetyl CoA; (c) A I $c h l$ plus acetyl CoA.

Fig. 4. Acetylation of chloramphenicol by extracts of $M$. fulvus $\mathrm{M}$ and its derivatives. Conditions for extraction and incubation ( $2 \mathrm{~h}$ ) were as in Fig. 2. (a) Strain M, (b) M2 chl, (c) $\mathrm{M}(\mathrm{S}-\mathrm{a}) \mathrm{chl}$, all plus acetyl CoA; (d) $\mathrm{M}(\mathrm{S}-\mathrm{a}) \mathrm{chl}$ without acetyl CoA.

M7 formed immature fruiting bodies containing few myxospores, and B(R I I $9-2), B\left(R_{I}\right)$ and $\mathrm{B}(\mathrm{S}-\mathrm{a})$ did not form fruiting bodies.

The tolerance of certain strains to higher concentrations of chloramphenicol was examined by picking colonies from CT agar containing $25 \mu \mathrm{g}$ of the $\mathrm{drug} / \mathrm{ml}$ on to $\mathrm{CT}$ agar containing 50, 75 and $100 \mu \mathrm{g} / \mathrm{ml}$. Strain $\mathrm{M}_{7}$ was inhibited by $50 \mu \mathrm{g} / \mathrm{ml}$. Strains AI(RI) $c h l$, $\mathrm{M}(\mathrm{RI}) c h l, \mathrm{M}(\mathrm{RI}$. I9) $c h l, \mathrm{M}(\mathrm{S}-\mathrm{a}) c h l$ and $\mathrm{M}(\mathrm{R} 478) c h l k a n$ were all tolerant to a concentration of $50 \mu \mathrm{g} / \mathrm{ml}$. With strains $\mathrm{AI}(\mathrm{RI}) c h l$ and $\mathrm{M}(\mathrm{S}-\mathrm{a}) c h l$, limited growth was discernible on $75 \mu \mathrm{g} / \mathrm{ml}$ after 2 weeks' incubation. The other strains did not grow on this concentration and all the strains were totally inhibited by $100 \mu \mathrm{g} / \mathrm{ml}$.

\section{Acetylation of chloramphenicol by Myxococcus strains}

Chloramphenicol resistance in $\mathrm{R}^{+}$strains of $E$. coli is due to chloramphenicol acetyltransferase (Shaw, 1967). The enzyme activity has been demonstrated in Myxococcus strains by 
Table 5. Effect of chloramphenicol on the spreading of Myxoccocus colonies

Myxococcus xanthus AI chl is a segregant from $\mathrm{AI}\left(\mathrm{R}_{\mathrm{I}}\right.$.19). Strain IM is a non-disperse clone of M. fulvus $\mathrm{M} ; 2 \mathrm{M}$ is a disperse growing clone of strain $\mathrm{M} ; \mathrm{M} 2$ and $\mathrm{M}(\mathrm{R} 57 \mathrm{~b})$ are both non-disperse.

Rate of increase of colony diameter $(\mathrm{mm} / \mathrm{h})$

$\begin{array}{lcc}\text { Strain } & \text { CT agar } & \begin{array}{c}\text { CT agar plus } \\ \text { chloramphenicol }\end{array} \\ \text { AI-I } & \mathrm{I} \cdot 8 & 0 \\ \text { AI(RI . I9) chl } & 2 \cdot \mathrm{I} & 0 \cdot 3 \\ \text { B } & \mathrm{I} \cdot 4 & 0 \\ \text { B(R478) chl } & \mathrm{I} \cdot 9 & 0 \cdot 9 \\ \text { B(R39) chl } & \mathrm{I} \cdot \mathrm{I} & 0 \cdot 8 \\ \text { IM } & 3 \cdot \mathrm{I} & 0 \\ \text { 2M } & 2 \cdot 5 & 0 \\ \text { M2 chl } & \mathrm{I} \cdot 2 & \mathrm{I} \cdot \mathrm{I} \\ \text { M(R478) chl } & 2 \cdot 4 & 0 \cdot 8 \\ \text { M(S-a) chl } & 2 \cdot \mathrm{I} & \mathrm{I} \cdot 0 \\ \text { M(R57b) chl } & \mathrm{I} \cdot 2 & \mathrm{I} \cdot 4 \\ \text { M(RI) chl } & 2 \cdot 8 & \mathrm{I} \cdot 6 \\ \text { M(RI . I 9) chl } & 2 \cdot 3 & \mathrm{I} \cdot 4\end{array}$

Table 6. Transfer of chloramphenicol resistance to $M$. xanthus B26 rif and $M$. fulvus M26 rif

Mixtures initially contained $5 \times 10^{7}$ c.f.u. of each strain $/ \mathrm{ml}$ except for the non-disperse strains which were inoculated as 2 to 3 spheres (see Methods). The numbers refer to rif chl recombinants per $10^{5}$ recipients (or in the case of controls, per $10^{5}$ organisms) after incubation. dis, Non-disperse strain.

\begin{tabular}{lccc} 
& \multicolumn{3}{c}{ Recipient } \\
Donor & B26 rif & M26 rif & None \\
M(R57b) chl dis & 4.5 & 60 & - \\
M(S-a) chl & 0.8 & 17.5 & $<0.04$ \\
M(R478) chl & 9.9 & 14.7 & $<0.04$ \\
M(RI) chl & 5.7 & 8.7 & $<0.05$ \\
M(RI . I9) chl & 2.2 & $<0.3$ & $<0.2$ \\
M7 chl dis & 25.0 & 2.6 & - \\
B(R390) chl & 11.6 & $<0.05$ & $<0.04$ \\
$\quad$ None & $<0.03$ & $<0.3$ &
\end{tabular}

measuring the conversion of $\left[{ }^{14} \mathrm{C}\right]$ chloramphenicol to acetyl $\left[{ }^{14} \mathrm{C}\right]$ chloramphenicol (see Methods). The bacteria were grown in CT medium containing chloramphenicol $(25 \mu \mathrm{g} / \mathrm{ml})$, harvested, washed twice with $\mathrm{CT}$ and assayed for the enzyme. Results of such assays are summarized in Figs. 2 to 4 . In $E$. coli the enzyme acetylates the 3-hydroxyl of chloramphenicol. A non-enzymic rearrangement to the I-acetate is followed by a second acetylation yielding some I,3-diacetyl chloramphenicol (Shaw, 1967). Figure 2 compares the activity of unfractionated extracts of $M$. xanthus AI(RI . I9) chl and E. coli J53(RIdrdI9). The Myxococcus extract is substantially less than that from $E$. coli. By using ammonium sulphateprecipitated protein (Fig. 3) the activity in M. xanthus AI(RI . 19) chl was shown to be totally dependent upon acetyl CoA. The activity (which in partially fractionated preparations yields no I,3-diacetyl chloramphenicol) is entirely absent from $M$. xanthus A I-I. The activity was examined in M. fulvus strains (Fig. 4): little activity was found in strain M (Fig. 4a); $M$. fulvus M2 chl showed slight activity (Fig. $4 b$ ); $M$. fulvus $\mathrm{M}(\mathrm{RI})$ chl (not shown) showed comparable activity to strain M2 and this activity was acetyl CoA-dependent; $M$. fulvus 


\section{Table 7. Transfer of rifampicin resistance between strains derived from $M$. xanthus в and M. fulvus $\mathrm{M}$}

Crosses were performed and scored as in Table 6 . The numbers are recombinants per $10^{5}$ recipients. 'Controls' refer to all the components of the crosses. All donor strains were rif; those carrying either $\mathrm{S}-\mathrm{a}$ or $\mathrm{m} 7$ were also $\mathrm{chl}$. The recipients were $f u$.

\begin{tabular}{l}
\multicolumn{1}{c}{ Cross } \\
Controls \\
B26 $/ \mathrm{m} 7 \times$ M27 \\
B26/m $7 \times$ B27 \\
B26 $($ S-a $) \times$ B27 \\
B26 $($ S-a $) \times$ M27 \\
M26 $($ S-a $) \times$ B27 \\
M26(S-a) $\times$ M27 \\
B26 6 M27 \\
B26 6 B27 \\
M26 6 M27 \\
M26 6 B27
\end{tabular}

\begin{tabular}{rr}
\multicolumn{2}{c}{ Recombinants } \\
fluchl \\
$<0.2$ & $<$ rif \\
$<0.2$ & $<0.2$ \\
3.0 & $<0.2$ \\
$<0.2$ & 1.0 \\
5.0 & 2.0 \\
3.0 & 10.6 \\
1.7 & 5.0 \\
- & 6.0 \\
- & $<0.2$ \\
-- & $<0.2$ \\
- & $<0.2$ \\
& $<0.2$
\end{tabular}

(S-a) chl showed greater activity (Fig. 4c); M. fulvus $\mathrm{M}(\mathrm{R} 478)$ chl kan (not shown) demonstrated high activity, comparable with strain $\mathrm{M}(\mathrm{S}-\mathrm{a}) \mathrm{chl}$.

The instability of the Chl phenotype and the difficulties of quantitative colorimetric enzyme assay have prevented satisfactory experiments to establish whether the enzyme is constitutive (as in $\mathrm{R}^{+}$strains of $E$. coli).

Strains $A, B, F_{t}$ and $M$ were grown for $I 5 h$ in the presence of non-inhibitory concentrations of $\left[{ }^{14} \mathrm{C}\right]$ chloramphenicol to a density of $10^{8} \mathrm{c}$.f.u. $/ \mathrm{ml}$. No acetylated chloramphenicols were detectable in the supernatant. The limits of the assay would detect a conversion of approximately $2 \%$ of chloramphenicol to acetylated products. These strains do convert acetyl chloramphenicols to chloramphenicol, presumably as a result of esterase activity (R. P. Burchard and J. H. Parish, unpublished).

\section{Transfer of drug resistance between Myxococcus strains}

Chloramphenicol resistance was transferred to strains of $M$. xanthus $\mathrm{B}$ and $M$. fulvus $\mathbf{M}$ when chloramphenicol-resistant myxococci were incubated with rifampicin-resistant recipients. The rif chl recombinants were allocated to strains $\mathrm{B}$ and $\mathrm{M}$ on the basis of their carotenoid spectra and thin-layer chromatograms (see Methods). Results of such crosses are summarized in Table 6 . In every case in which the cross involved one B-strain and one $\mathrm{M}$-strain, carotenoid analysis of the recombinants confirmed that they were derived from the recipient.

Recombinant strains are designated as, for example, M26(R478) chl rif. The recombinants from the cross $\mathrm{M} 7 \times \mathrm{B} 26$ are referred to as $\mathrm{B} 26 / \mathrm{m} 7 \mathrm{chl}$ rif. The stability of chloramphenicol resistance in the strains examined [B26/m7, в26(R390), м26(S-a) and B26(S-a)] is qualitatively similar to that in the donors. After overnight growth in CT medium the e.o.p. on chloramphenicol was $\mathrm{IO}^{-1}$ to $\mathrm{IO}^{-4}$. The e.o.p. for chloramphenicol-grown bacteria was approximately $100 \%$; both types of culture showed an e.o.p. of $80 \%$ on rifampicin.

Crosses were attempted using B26, M26 and every type of rif chl recombinant in Table 7 as donor and $\mathrm{M} 27 f l u$ and $\mathrm{B} 27 \mathrm{flu}$ as recipients. Recombinants $c h l f l u$ were obtained with comparable frequencies to those shown in Table 6. The mixtures were also assayed for 
flu rif recombinants. The only successful crosses employed B26(S-a), M26(S-a) or B26/m7 as donor (Table 7$)$. Strain M26 (R478) is probably a successful donor of rifampicin resistance but data are not presented and there was a low background of fluorouracil-resistant colonies produced by the donor. Strains of B26 or M26 carrying chloramphenicol resistance derived from R57b, RI, RI . I9 or R390 were not successful donors (comparable with $R^{-}$B26 and M26, Table 7).

\section{DISCUSSION}

The transfer of drug resistance to Myxococcus strains from eubacterial $\mathrm{R}$ factors extends the number of Gram-negative bacteria between which plasmid transfer is possible. The mechanism of the transfer remains unclear. The data on RIdrdI9 and its derivatives (Table 3) imply that the transfer function that operates in E. coli conjugation is not involved, but the species of the donor is significant (transfer from $S$. marcescens did not occur). There are no data clearly indicating the nature of the chloramphenicol-resistance determinant in strains such as $M$. xanthus AI(RI . 19) $c h l$ and $M$. fulvus (S-a) $c h l$, and analysis of the DNA content of such cells is likely to be complicated by the presence of cryptic plasmids in Myxococcus strains (N. L. Brown and J. H. Parish, unpublished). However, the instability of the chloramphenicol resistance is suggestive of a plasmid. The $\mathrm{R}^{+}$Myxococcus strains do not transfer resistance to $\mathrm{R}^{-}$strains of $E$. coli under the conditions of incubation used here.

The data imply that there is a difference between the abilities of Myxococcus strains productively to assimilate extrachromosomal DNA from other bacteria. It is possible that strains $\mathrm{FB}_{\mathfrak{t}}$ and $\mathrm{A}$ are either restrictive or have different conditions of competence. Strains $\mathrm{B}$ and $\mathbf{M}$ were used in attempts to transfer a chromosomal marker (rif) in Myxococcus (Table 7). These results provide preliminary evidence that genetic exchange is possible. The genetic element $\mathrm{m} 7 \mathrm{chl}$ is potentially valuable for further studies on gene transfer.

The transfer of genes (including $\mathrm{m}_{7} \mathrm{chl}$ ) between strains B and $\mathrm{M}$ and the fact that strain M acts as host to $M$. xanthus phage MXI suggests that these two strains are closely related and raises the question of the taxonomic status of the strain M. For the present, I propose that the designation $M$. fulvus for strain $\mathrm{M}$ be tentatively retained.

I am grateful to Drs S. Baumberg and S. Dennison, Department of Genetics, University of Leeds and Professor R. P. Burchard, Department of Biological Science, University of Maryland, Baltimore County for gifts of strains and helpful discussion; to Dr H. Kühlwein, Botanische Institut I der Universität, Karlsruhe and Dr K. Murray, Department of Molecular Biology, University of Edinburgh for gifts of strains; and to Mrs M. Webster for excellent technical assistance. The work was supported by a research grant from the Science Research Council.

\section{REFERENCES}

BURCHARD, R. P. (I974). Growth of surface colonies of the gliding bacterium Myxococcus xanthus. Archiv für Mikrobiologie 96, 247-254.

BurChaRd, R. P. \& DWORKIN, M. (I966a). A bacteriophage for Myxococcus xanthus: isolation, characterisation and relation of infectivity to host morphogenesis. Journal of Bacteriology 91, 1305-I3I 3.

BurChard, R. P. \& Dworkin, M. (I966 b). Light-induced lysis and carotenogenesis in Myxococcus xanthus. Journal of Bacteriology 9I, 535-545.

Clowes, R. C. \& HAYEs, W. (I968). Experiments in Microbial Genetics. Oxford: Blackwell Scientific Publications.

Datta, N. \& Hedges, R. W. (I972). Host range of R factors. Journal of General Microbiology 7o, 453-460.

Davis, J. E., Strauss, J. H. \& Sinsheimer, E. L. (196I). Bacteriophage MS2: another RNA phage. Science, New York 134, 1427. 
Dworkin, M. (1962). Nutritional requirements for vegetative growth of Myxococcus xanthus. Journal of Bacteriology 84, 250-257.

Dworkin, M. (1973). Cell-cell interactions in the Myxobacteria. Symposia of the Society for General Microbiology 23, $125-142$.

Dworkin, M. \& SADLER, W. (I966). Induction of cellular morphogenesis in Myxococcus xanthus. I. General description. Journal of Bacteriology 91, 15 I 6-1 5 I 9.

Hedges, R. W. \& DatTA, N. (I97I). $f^{-}$R factors giving chloramphenicol resistance. Nature, London 234, 220-22I.

Hedges, R. W., Datta, N., Coetzee, J. N. \& Dennison, S. (I973). R factors from Proteus morganii. Journal of General Microbiology 77, 249-259.

Hedges, R. W., Rodriguez-Lemoine, V. \& Datta, N. (I975). R factors from Serratia marcescens. Journal of General Microbiology 86, 88-92.

INGRAM, L. C. (1973). Deoxyribonucleic acid-deoxyribonucleic acid hybridization of R factors. Journal of Bacteriology II5, I I 30-I I 34 .

Kleinig, H. \& Reichenbach, H. (1973). Biosynthesis of carotenoid glucoside esters in Myxococcus fulvus (Myxobacteriales): inhibition by nicotine and carotenoid turnover. Biochimica et biophysica acta 306, 249-256.

Lawn, A. M., Meynell, E., Meynell, G. G. \& Datta, N. (1967). Sex pili and the classification of sex factors in the Enterobacteriaceae. Nature, London 216, 343-346.

Lowry, O. H., Rosebrough, N. J., Farr, A. L. \& Randall, R. J. (I95I). Protein measurement with the Folin phenol reagent. Journal of Biological Chemistry 193, 265-275.

REICHENBACH, H. (I965). Untersuchungen an Archangium violaceum. Ein Beitrag zur Kenntnis der Myxobacterien. Archiv für Mikrobiologie 52, 376-403.

Saunders, J. R. \& GRINSTed, J. (1972). Properties of RP4, an R factor which originated in Pseudomonas aeruginosa S8. Journal of Bacteriology $\mathbf{1 2}$, 690-696.

SHAw, W. V. (1967). The enzymic acetylation of chloramphenicol by extracts of R factor-resistant Escherichia coli. Journal of Biological Chemistry 242, 687-693.

SHAW, W. V. \& BRodSKY, R. F. (1968). Characterization of chloramphenicol acetyltransferase from chloramphenicol-resistant Staphylococcus aureus. Journal of Bacteriology 95, 28-36.

Witchitz, J. L. \& Chabbert, Y. A. (I972). Résistance transférable à la gentamicine. II. Transmission et liaisons du caractère de résistance. Annales de l'Institut Pasteur 122, 367-378.

Yoshimori, R., Roulland-Dussoix, D. \& BoYeR, H. W. (1972). R factor-controlled restriction and modification of deoxyribonucleic acid: restriction mutants. Journal of Bacteriology I12, I 275-1279. 